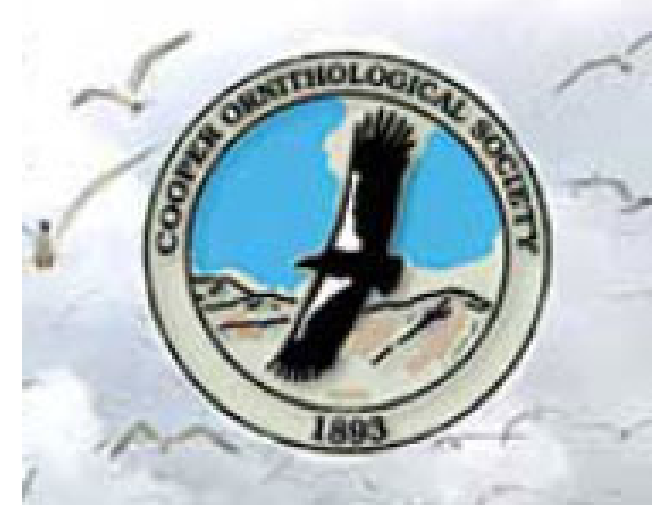

Molt and the Basic Plumage of Male Harlequin Ducks

Author(s): Fred Cooke, Gregory J. Robertson, R. Ian Goudie, W. Sean Boyd

Reviewed work(s):

Source: The Condor, Vol. 99, No. 1 (Feb., 1997), pp. 83-90

Published by: University of California Press on behalf of the Cooper Ornithological Society

Stable URL: http://www.jstor.org/stable/1370226

Accessed: 23/04/2012 23:10

Your use of the JSTOR archive indicates your acceptance of the Terms \& Conditions of Use, available at http://www.jstor.org/page/info/about/policies/terms.jsp

JSTOR is a not-for-profit service that helps scholars, researchers, and students discover, use, and build upon a wide range of content in a trusted digital archive. We use information technology and tools to increase productivity and facilitate new forms of scholarship. For more information about JSTOR, please contact support@jstor.org. 


\title{
MOLT AND THE BASIC PLUMAGE OF MALE HARLEQUIN DUCKS ${ }^{1}$
}

\author{
Fred CoOke and Gregory J. Robertson \\ Department of Biological Sciences, Simon Fraser University, \\ Burnaby BC V5A 1S6, Canada \\ R. IAN Goudie And W. Sean Boyd \\ Pacific Wildlife Research Centre, Canadian Wildlife Service, \\ 5421 Robertson Road, Delta, BC V4K 3Y3, Canada
}

\begin{abstract}
Using observations on 28 individually marked male Harlequin Ducks from mid-June until late November, we describe plumage changes which occur as individuals proceed from the alternate plumage through basic to the return of the new alternate plumage. We also describe the timing of these events, at the individual and population level. Conspicuous white tertial feathers which become visible early in the period of the basic plumage present a challenge to existing theories to explain the function of the drab basic plumage. We hypothesize that these feathers act as a badge of quality and are used as a sexual signal to other birds. Intra-sexual competition among males to assess the quality of rival males prior to subsequent pair formation is a proposed function of this feather badge.
\end{abstract}

Key words: alternate plumage, badges, basic plumage, Harlequin Ducks, Histrionicus histrionicus, molt, sexual selection.

\section{INTRODUCTION}

The males of most species of holarctic Anatidae show two distinct adult plumages each year, a basic plumage, which is relatively inconspicuous, and an alternate plumage which is often brightly colored (Palmer 1976). The dull basic plumage also is referred to as the eclipse plumage (Witherby et al. 1939), and closely resembles the body plumage of the female. The change from alternate to basic and from basic to alternate involves two replacements of body feathers. While drakes are in basic plumage, a complete molt of remiges and rectrices occurs and birds become flightless for a period of several weeks. They usually move to specific, often secluded, locations before the prebasic molt. These places are usually distinct from both breeding and wintering locations (Salomonsen 1968).

Because of the cryptic features of the male eclipse plumage, its association with the flightless period and the utilization of secluded locations during this period, it usually has been assumed that the main function of the basic plumage is to reduce detection by predators during a

\footnotetext{
${ }^{1}$ Received 16 June 1996. Accepted 3 September 1996.
}

period of increased vulnerability (Hochbaum 1944, Owen and Black 1990, Hohman et al. 1992). However, other hypotheses have been proposed. Bailey (1981) questioned the value of cryptic plumages for diving ducks which spent much time on open water where they could escape predators by diving. He proposed that a dark colored basic plumage may confer a thermal advantage by reducing the temperature gradient between skin and plumage and potentially reducing heat loss. A third explanation could be referred to as the default hypothesis. We might expect feathers to be without conspicuous markings unless there were some selective advantage for conspicuous plumage. The selective pressure for bright alternate plumages in many holarctic waterfowl is presumed to be a result of strong directional sexual selection. During the time when birds are in basic plumage this selection is presumably absent and based on the assumption that elaborate plumage patterns are energetically more expensive than simple ones, one might expect feathers to be simple, lighter, cheaper to produce and lacking in color variety (Wielecki 1987).

The generally short, 3 to 6 month duration in which drakes are in basic plumage, relative to the time in alternate plumage, has been broadly interpreted in terms of sexual selection (Ander- 
son et al. 1992). Pressure on males to acquire a mate prior to arrival on the breeding grounds and the advantages for females to have a male guarding her from conspecific disturbance during the winter so she can forage efficiently can lead to directional selection for earlier and earlier pair formation. This gives a selective advantage to drakes that develop a bright alternative plumage as soon as possible (Rohwer and Anderson 1988). Under this scenario the relative duration of the basic and alternate plumages in the drakes can be thought of as being determined by the fitness advantages associated with crypticity during the basic plumage period relative to the fitness advantages associated with attracting a high quality mate during the alternate plumage period. Although the relative fitness of these countervailing pressures has not been measured, Owen and Black (1990) argue that reduced predation pressure on seaducks might increase the length of the molting period, and presumably increase the duration of the period when the birds are in basic plumage.

In this study, we: (1) describe the changes in conspicuous body plumage of individual male Harlequin Ducks (Histrionicus histionicus) from early June until early October, during which time the birds progress from the alternate plumage, through pre-basic molt into the basic plumage and then through the pre-alternate molt into their new alternate plumage. We concentrate on those visible features of the plumage which might provide signals to predators (crypticity or not) or to conspecifics (allowing species, sex or individual recognition) insofar as these might give us clues to the possible function of the plumage patterns, (2) record behavioral changes during this period associated with plumage changes, which may provide hints as to the function of the plumages, and (3) examine the basic plumage of male Harlequin Ducks in light of three hypotheses outlined above (a) crypticity, (b) thermal advantage and (c) default, which have been proposed to explain the lack of conspicuous markings and color in the basic plumage of ducks.

\section{METHODS}

Unlike several recent molt studies in waterfowl (Hohman and Crawford 1995, Thompson and Drobney 1995) that follow the methodology of Billard and Humphrey (1972) in collecting large samples of birds at intervals through the appro- priate time of year, our approach relies instead on observing individually marked live birds frequently through the period. The advantages of this latter method is that it allows us to (1) observe the plumage changes of known individuals which are relevant to the questions on the function(s) of the basic plumage which we posed above, (2) examine the timing and duration of the plumage changes, and (3) observe the behaviors of the birds during this period in order to investigate behavioral correlates of the plumage patterns.

A molting and wintering population of Harlequin Ducks comprising between 100 and 150 birds occurs on a $5.5 \mathrm{~km}$ stretch of rocky waterfront of the Pacific Ocean between the communities of Crescent Beach and White Rock in southwest British Columbia (Savard 1988). On 26 July 1994, 43 Harlequin Ducks from this population were captured during the flightless period using kayaks and a drive-trap (Clarkson and Goudie 1994). Each bird was aged, sexed and marked with an individually identifiable colored tarsal band with 2 alphanumerics on the band. Tarsal bands allow identification of individuals because Harlequin Ducks often haul out on to rocks.

Adult males that returned to the molting area the following year were closely monitored from 9 June 1995 until early November 1995. At about three day intervals, an observer walked along the study site with a 15-60X telescope to assess the population. Sex, age, group structure, behavior, and location of all ducks present were recorded. Additionally, several plumage features which change during the molt period were recorded. Individuals were classified as being in alternate plumage, basic plumage or transitional (either pre-basic or pre-alternate molt). It was always possible to determine whether a bird was in pre-basic or pre-alternate molt by the timing of the event and the presence of intermediate plumages. Evidence of feather on any tract loss or gain indicated that a bird was undergoing a molt. Observations of the birds were made from within $50 \mathrm{~m}$ and we are confident that birds in any stage of an intermediate plumage could be identified. Furthermore, birds were observed intensively (approximately 10 to 15 minutes) until all aspects of their plumage could be seen before the assessment of their molt status was made. All birds were seen a minimum of six, and up to 23 times during the 
course of the study. Additionally, the stage of the rectrial and remigial molt was assessed by observation.

\section{TIMING OF MOLT}

Unfortunately the molt stage of each and every individual could not be assessed daily. Available data can only provide a range of dates within which the various molt stages were initiated or completed. We used a method assessing daily probabilities of individuals starting or finishing various stages of the molt in order to estimate the length of time for completion of the various stages. For example, a bird seen in alternate plumage on 10 June and first seen undergoing the pre-basic molt on 13 June could have initiated the pre-basic molt on any one of the days within that time period. We conservatively estimate that this bird had equal probabilities of initiating the pre-basic molt on any one of the 4 days during that interval. Similarly if this hypothetical bird was last seen undergoing prebasic molt on 26 June and seen in basic plumage on 3 July, we have minimum and maximum estimates for the length of time for the pre-basic molt. For this bird the maximum length of time for the pre-basic molt to be completed is 23 days (10 June to 3 July), the minimum period is 13 days (13 June to 26 June). Each day within this period was assigned an equal probability that the pre-basic molt took that length of time. In this case 13 to 23 days would be given a probability of $0.0909(1 / 11)$ and lengths of time outside that period would be given 0 probability. These probabilities were then summed for all birds for which there was available data, resulting in a probability density function (pdf) for the length of time each stage needed to be completed. The median of this distribution was taken as the best estimate of the length of time to complete each stage of the molt. This method is entirely analogous to maximum likelihood estimation, except that we used the median value from the pdf and not the highest value, as our pdfs contained occasional outlying values, probably due to low sample size. Ninety-five percent confidence limits were obtained directly from the pdfs. The strength of this method is that it gives higher weights to birds that were seen frequently because the range for the intervals are smaller, and the associated daily probabilities are larger. Taking means of ranges provides a biased estimate, as birds not seen for long periods artificially extended the length of the estimate.

\section{ASSESSMENT OF GROUPS}

Groups of Harlequin Ducks were defined as a set of individuals present in a restricted section of the study area and generally interacting with each other in some way or performing similar behaviors. The study area was divided into 39 sections of equal length approximately $160 \mathrm{~m}$ along the shoreline that we surveyed. To assess how ducks grouped themselves over the whole study area, we recorded the number of birds, including zero values, in each of the 39 sections. We then calculated the variance-to-mean ratio of group sizes seen over the study area as a whole. Variance-to-mean ratios of 1 indicate that group sizes are following a Poisson distribution, suggesting that birds are distributing themselves independently of local habitat differences and/or the presence of other birds. Values less than 1 indicate that birds are actively avoiding one another, and values above 1 suggest that birds are clumping at some sites and not using others (Sokal and Rohlf 1981).

Spearman rank correlations were used to ascertain whether there was a positive, negative, or no association between the sexes in all of the groups seen on a given survey. Spearman rank correlations were used instead of parametric Pearson correlations to avoid overweighting observations with many birds in a single group. One large grouping of males and females is sufficient to provide a positive Pearson correlation, even if all of the rest of the smaller groups in the study area are showing a negative association between the sexes.

\section{RESULTS}

\section{CHRONOLOGY OF RETURNING MALES}

Of 37 adult males which were color banded in 1994, 28 returned after breeding to molt at the study site in 1995 . The dates on which individual males were first seen ranged from 9 June to 19 July, a period of 40 days. Half of the birds (14) were first seen in alternate plumage, one quarter (7) were seen just after they had begun the pre-basic molt, five of the birds were well into their pre-basic molt and two birds were first seen already in their basic plumage. Recognizing that birds were not necessarily observed immediately after they arrived, these data suggest that most birds arrived at the molting area in 
TABLE 1. Estimated number of days male Harlequin Ducks spent in various plumage stages at White Rock, BC, 1995.

\begin{tabular}{lrc}
\hline \hline \multicolumn{1}{c}{ Molt stage } & $n$ & $\begin{array}{c}\text { Estimated number of } \\
\text { days (95\% C.I.) }\end{array}$ \\
\hline Undergoing pre-basic & 15 & $20(7-32)$ \\
Basic (cryptic) & 26 & $18(3-41)$ \\
$\begin{array}{l}\text { Basic (white tertials } \\
\text { visible) }\end{array}$ & 8 & $34(22-54)$ \\
Undergoing pre-alternate & 24 & $15(1-35)$ \\
\hline
\end{tabular}

alternate plumage and soon began molting body feathers.

\section{MOLT CHRONOLOGY}

Table 1 presents the estimated number of days that male Harlequin Ducks spent in each stage of the molt. Pre-basic molt of the conspicuous body feathers lasted an estimated 20 days. We have divided the period when males are in their full basic plumage into two stages. One is the period when males showed no conspicuous body plumage, having dropped all conspicuous body feathers. They were very similar to females except for darker feathers on the belly and a general richer brown for the body plumage. This plumage fits the description by Johnsgard (1965). The length of this stage is estimated to be about 18 days. Old remiges are dropped at this time. The second stage is when two white-centered tertials become clearly visible on each side of the lower back. The visibility of these tertial feathers is enhanced by the loss of the remiges. These feathers are the new basic plumage tertials, which are part of the body feathers rather than the remiges (Stresemann and Stresemann 1966). Old rectrices were dropped early in this stage and new remiges began to grow. This stage was estimated to last an average of 34 days and is illustrated in several standard field guides and handbooks (e.g., Witherby et al. 1939). Males were much more conspicuous and distinct from the females during this plumage because of the white tertials. The total time that birds are in basic plumage as detected from the visual characters which can be identified in the field is on average 52 days.

The white tertials are shed at the beginning of the pre-alternate molt; these feathers lasted slightly more than 34 days, allowing for some days of growth before they are visible in the field. At the early stages of the pre-alternate molt, males again are relatively inconspicuous due to the absence of the white tertials, but the plumage patterns of the alternate plumage reappear quickly and synchronously. Included in the alternate plumage pattern is a new set of three white tertials on each side. These are larger and have a different shape from those that precede them and they are the last of the alternate plumage body feathers to re-appear. Prealternate molt lasts an average of 15 days.

At the population level, although the sample size is small, males began the pre-basic molt in mid-June (Fig. 1). All males were in basic plumage during the last week of July through most of August. The first males began the prealternate molt in early September and the last male still with signs of molt was seen in midOctober.

The total estimated period for a male Harlequin Duck from the start of the conspicuous stage of the pre-basic molt to the return to his visible alternate plumage feathers is 87 days or approximately three months.

\section{DISTRIBUTIONAL PATTERNS}

Male Harlequin Ducks were highly clumped from their arrival in June and July through the end of September (Fig. 2). In October and November, when molting was completed, the birds tend to disperse throughout the habitat and the coefficient of dispersion approached 1 (Fig. 2). In August and September there was a tendency for the ducks to segregate into same sex groupings (Fig. 3) as evidenced by the negative correlation coefficients. In October and November, the correlations between the number of males and females in any given group became positive, suggesting pairing among the birds.

\section{DISCUSSION}

Male Harlequin Ducks returned to the study location prior to molt and began to lose body feathers soon after arrival. They hauled out frequently, allowing us to recognize them individually. Because birds were individually color banded we were able to follow the progress of the molt from alternate to basic and back to alternate in 28 individuals, and at the same time observe distributional patterns during the process. Such an analysis has rarely, if ever, been possible in holarctic Anatidae because of the difficulty of following known individuals and the inaccessibility of most molting locations. 


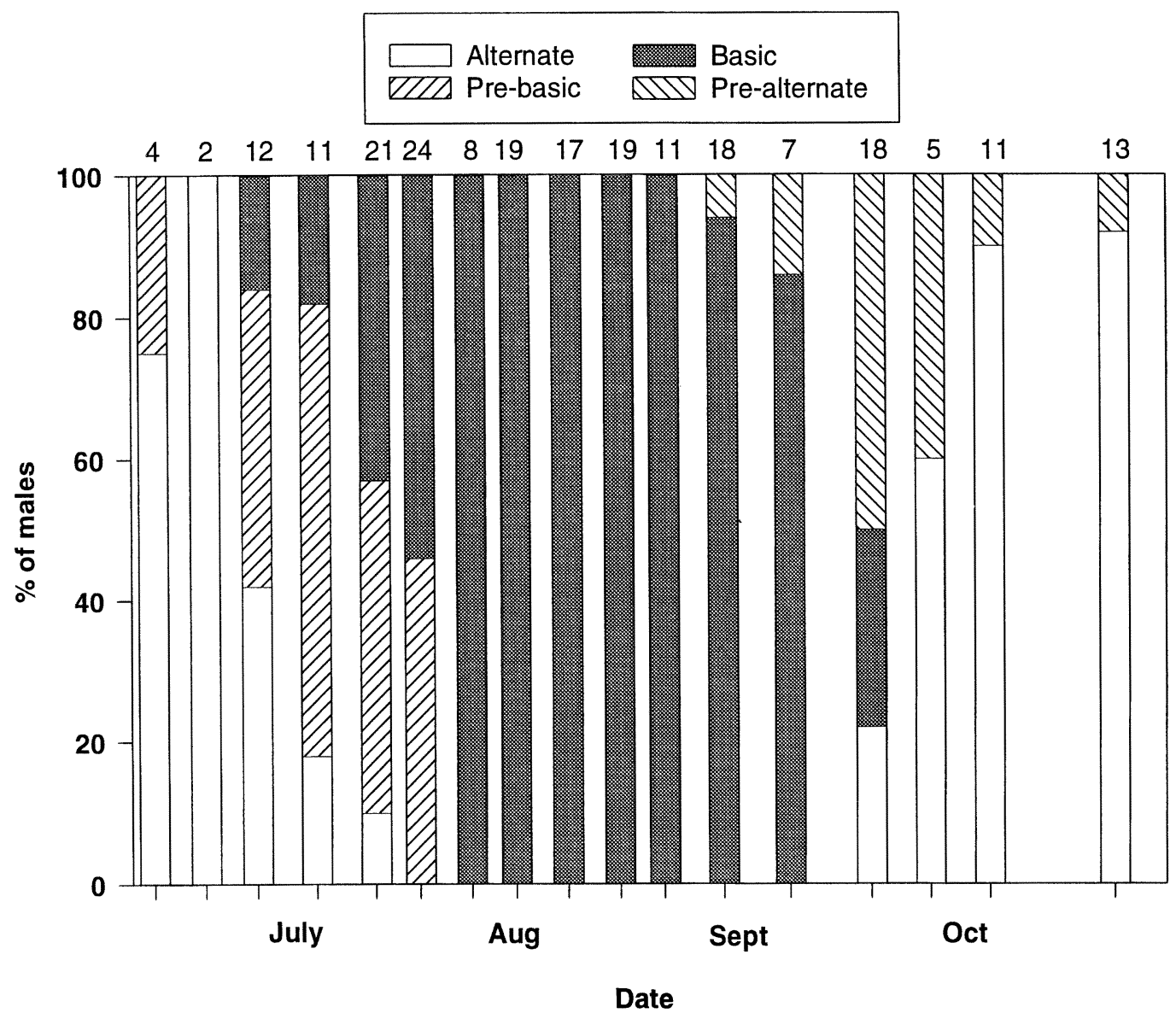

FIGURE 1. Proportion of banded male Harlequin Ducks in each of the four plumage stages at White Rock, BC., 1995.

A description of the basic plumage does not necessarily allow us to infer function associated with the two stages. Although non-adaptive explanations cannot be refuted, the basic plumage patterns described above allow us to explore the hypotheses described earlier. At the beginning of the basic plumage, the males are indeed female like and cryptic apart from the facial markings which both sexes carry. Throughout the period and in contrast to their distribution during most of the winter, the males form into groups and tend to keep separate from the females. They spend more time hauled out on rocks than they do at any other time of year (F. Cooke and G. J. Robertson, unpubl. data). Clumping may provide increasing protection from predators. If birds are more vulnerable to predators while on the water than on the land, then hauling out may be an anti-predator mechanism. On one occa- sion three birds were seen to suddenly and rapidly scoot across the water towards the land, as if in response to an underwater threat. However, in general, Harlequin Ducks, in common with other diving ducks, respond to land based and aerial predators by heading to open water and diving if attacked (Bailey 1981). It has even been suggested that the alternate plumage of the drake Harlequin Duck is cryptic when the birds are swimming in rough water or bobbing around in high seas (Fleischner 1983).

There are better and more obvious explanations for an increasing tendency to haul out during molt. There is a strong correlation between preening and hauling out (Gowans et al., in press), and the enhanced preening required during the molt of body feathers is probably easier to perform on land than in the water. Moreover hauling out remains a frequent activity during 


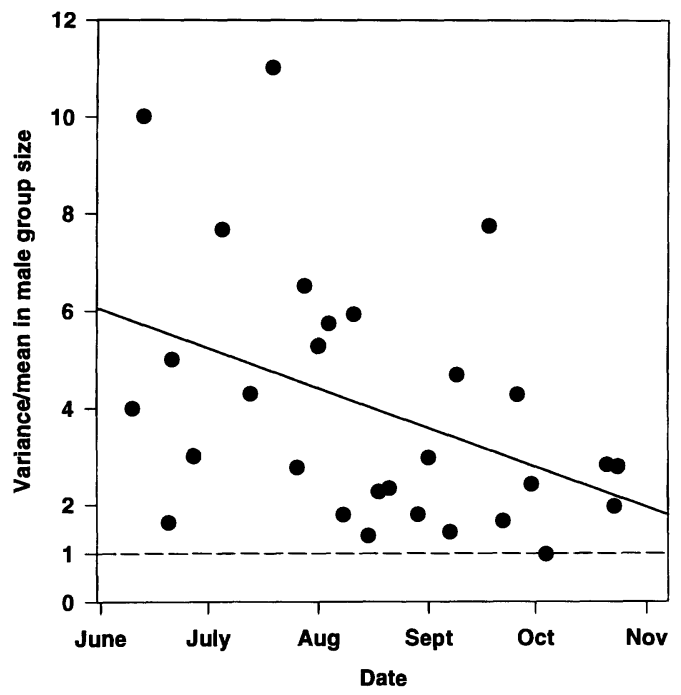

FIGURE 2. Coefficients of dispersion (CD; variance/mean ratio) in male Harlequin Duck group size over the molting season at White Rock, BC., 1995. Values of 1 indicate random distribution of individuals over the available habitat. There is a significant decline in the $\mathrm{CD}$ over the season $\left(F_{1,27}=5.6\right.$, $P=0.025$ ).

October when birds have re-acquired their alternate plumage (Gowans et al., in press). Evidence that the basic plumage acts as an antipredator mechanism during the first stage of the basic plumage is weak at best. Similarly there is little evidence for the heat loss hypothesis. Harlequin drakes are in basic plumage during June, July and August, the three warmest months of the year. Furthermore, there is no clear relationship in the heat retention capabilities of different plumage colors (Walsberg 1982, Beasley and Ankney 1988).

In the second stage of the basic plumage there is even less evidence for the crypticity hypothesis and considerable evidence against it. The appearance of the white tertial feathers during the basic stage of the body plumage is a puzzle, if one is seeking adaptive explanations for the plumage patterns. These feathers detract from the crypticity of the birds at least to human eyes. Perhaps it could be argued that cryptic plumage is no longer necessary because the birds regain flight capability in this second stage. Nevertheless this does not provide an explanation as to why the feathers should be white rather than dark brown like the others, nor the fact that the conspicuous tertials appear well before the

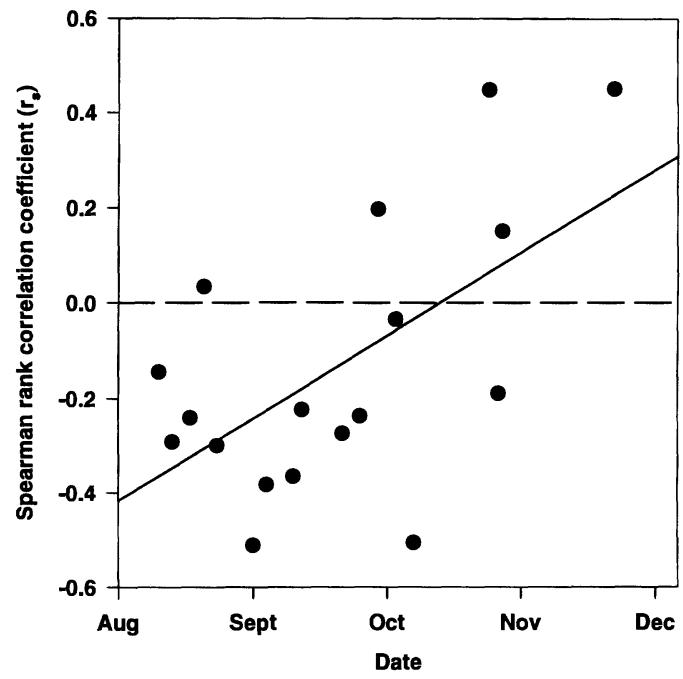

FIGURE 3. Spearman rank correlations between the number of male and female Harlequin Duck individual groups over the molting and post-molt season at White Rock, BC., 1995. There is a significant increase in the correlations over the season $\left(F_{1,15}=\right.$ $8.63, P<0.001)$.

birds can fly again. Neither the heat loss nor the default hypothesis provide an explanation for the white tertials and we must seek an explanation elsewhere.

We theorize that the white tertials serve as a badge of quality. The function of a badge is to provide a recognizable character indicating the quality of individuals in the population (Rohwer and Ewald 1981). To explore this idea further it is necessary to know more about the role of the white tertials in birds with complete alternate plumage. As the new alternate plumage develops, new white tertials appear later than the other visual plumage characters and when the feathers are fully grown they are larger than the ones present in the basic plumage. Initially they have a dark border around the white inner parts of the feather, but from a limited examination of museum specimens (F. Cooke, unpubl. data), this border may erode away during the winter. Another unique feature of these feathers is that they may be absent or present dependent on the age of the male. Immature and sub-adult birds either do not have them, or they are small and inconspicuous. A detailed study of the relationship between age and extent of white tertials has 
not been carried out, but would be most valuable. The white tertials also could provide evidence to other birds of the timing of molt. Those birds which enter molt early display the feathers earlier than those which begin later and this may provide important information to potential competitors later when active competition occurs among males for mates (Hepp 1988). Males are generally not able to successfully attract a mate until they have completed the pre-alternate molt (Wishart 1983).

The variability of the tertials, both in terms of the bird's age and as a signal of the timing of molt could provide a good indicator to other birds of the condition or quality of the bird. If this information is important in assessing other birds in the population, then one can understand why such an apparently unnecessary feature should become conspicuous in the middle of the period when birds are in basic plumage. Badges indicating quality may be important either in terms of intra- or inter-sexual interactions.

Our behavioral data provide evidence that when birds are in basic plumage, they associate in predominantly male groups which suggests that the white feathers are providing information to members of the same sex. Birds which molt in the area remain in the area afterwards and actively compete for females as soon as they regain their alternate plumage (F. Cooke and G. J. Robertson, unpubl. data). Advanced knowledge of the quality of rival males could well be useful for the individuals who are competing. Drakes in other duck species are known to sort themselves into a dominance hierarchy before pairing. Males at the top of the hierarchy pair first and so on down the hierarchy (McKinney 1992). The white tertials may be a major clue in the establishment of this hierarchy.

We proposed three hypotheses to explain the drab coloration of basic plumaged drakes. While our data provide little support for these hypotheses, none of them could explain the presence of white tertial feathers in the basic plumage. We theorize that these feathers act as a badge of quality, which may be useful during intra-sexual competition among males during later pair formation.

\section{ACKNOWLEDGMENTS}

Leigh Fredrickson and an anonymous reviewer provided helpful comments on an earlier draft. We would like to thank the following for their financial support of the Harlequin Duck project: the Pacific and Yukon Region of the Canadian Wildlife Service, the British Columbia Waterfowl Society, the Institute for Waterfowl and Wetlands Research, the Natural Science and Engineering Research Council of Canada (NSERC), and the Chair of Wildlife Ecology, Simon Fraser University. We thank Billie Gowans and Carl Hofbauer for help with the collection of field data.

\section{LITERATURE CITED}

Anderson, M. G., J. M. Rhymer, and F. C. Rohwer. 1992. Philopatry, dispersal and the genetic structure of waterfowl populations, p. 365-395. In B. D. J. Batt, A. D. Afton, M. G. Anderson, C. D. Ankney, D. H. Johnson, J. A. Kadlec, and G. L. Krapu [eds.], Ecology and management of breeding waterfowl. Univ. Minnesota Press, Minneapolis.

BAILEY, R. O. 1981. The post-breeding ecology of the Redhead Duck (Aythya americana) on Long Island Bay, Lake Winnipegosis, Manitoba. Ph.D. diss. McGill Univ., Montreal.

Beasley, B. A., And C. D. Ankney. 1988. The effect of plumage colour on the thermoregulatory abilities of Lesser Snow Goose (Chen caerulescens caerulescens) goslings. Can. J. Zool. 66:13521358.

Billard, R. S., ANd P. S. Humphrey. 1972. Molts and plumages in the Greater Scaup. J. Wildl. Manage. 36:765-774.

Clarkson, P., and R. I. Goudie. 1994. Capture techniques and 1993 banding results for molting Harlequin Ducks in the Strait of Georgia, p. 11-14. In Proc. 2nd Annual Harlequin Duck Symposium, Harlequin Duck Working Group, Ladner, BC.

FLEISCHNER, T. L. 1983. Natural history of Harlequin Ducks wintering in northern Puget Sound. M.Sc. thesis, Western Washington Univ., Bellingham, WA.

Gowans, B., R. J. Robertson, and F. Cooke. In press. Behaviour and chronology of pair formation in Harlequin Ducks (Histrionicus histrionicus). Wildfowl.

Hepp, G. R. 1988. Benefits, costs and determinants of dominance in American Black Ducks. Behaviour 109:223-234.

Hochbaum, H. A. 1944. The Canvasback on a prairie marsh. Am. Wildl. Inst., Washington, DC.

Hohman W. L., C. D. Ankney, and D. H. Gordon. 1992. Ecology and management of postbreeding waterfowl, p. 128-189. In B. D. J. Batt, A. D. Afton, M. G. Anderson, C. D. Ankney, D. H. Johnson, J. A. Kadlec, and G. L. Krapu [eds.], Ecology and management of breeding waterfowl. Univ. Minnesota Press, Minneapolis.

Hohman W. L., and R. D.Crawford. 1995. Molt in the annual cycle of Ring-necked Ducks. Condor 97:473-483.

JohnSGARD, P. A. 1965. Handbook of waterfowl behavior. Cornell Univ. Press. Ithaca, NY. 
McKinney, F. 1992. Courtship, pair formation and signal systems, p. 214-250. In B. D. J. Batt, A. D. Afton, M. G. Anderson, C. D. Ankney, D. H. Johnson, J. A. Kadlec, and G. L. Krapu [eds.], Ecology and management of breeding waterfowl. Univ. Minnesota Press, Minneapolis.

Owen M., And J. M. Black. 1990. Waterfowl ecology. Blackie and Son, London.

PALMER, R. S. 1976. Handbook of North American birds. Vols 2 and 3. Yale Univ. Press, New Haven, CT.

Rohwer, F. C., And M. G. Anderson. 1988. Female biased philopatry, monogamy and the timing of pair formation in waterfowl. Current Ornithol. 5:187-221.

Rohwer, S., AND P. W. Ewald. 1981. The cost of dominance and advantages of subordination in a badge signaling system. Evolution 35:441-454.

SAlomonsen, F. 1968. The molt migration. Wildfowl 19:5-24.

SAvARD, J-P. L. 1988. A summary of current knowledge on the distribution and abundance of moulting seaducks in the coastal waters of British Columbia. Technical Report Series No. 45. Cana- dian Wildlife Service, Pacific and Yukon Region, BC.

Sokal, R. R., And F. J. Rohlf. 1981. Biometry, 2nd ed. W. H. Freeman, San Francisco.

Stresemann, E., and V. Stresemann. 1966. Die Mauser der Vögel. J. Ornithol. 107: Sonderheft $1-446$.

Thompson, J. E., ANd R. D. DRobney. 1995. Intensity and chronology of post-reproductive molts in male Canvasbacks. Wilson Bull. 107:338358.

WALSBERG, G. E. 1982. Coat color, solar heat gain, and conspicuous plumage in the Phainopepla. Auk 99:495-502.

WIELECKI, D. J. 1987. Aspects of Mallard nutrition during moult. M.Sc. thesis, Univ. Manitoba, Winnipeg, Manitoba.

Wishart, R. A. 1983. Pairing chronology and mate selection in the American Wigeon (Anas americana). Can. J. Zool. 61:1733-1743.

Witherby, H. F., F. C. R. Jourdain, N. F. Ticehurst, AND B. W. TuCKer. 1939. The Handbook of British birds. Vol. 3 hawks to ducks. H. F. \& G. Witherby, London. 